\title{
アルミナ担持硫化モリブデン触媒の水素化活性と 水素化分解活性の制御
}

\section{一アルミナ担体の調製手法が触媒基本活性に与える影響一}

西嶋 昭生 ${ }^{\dagger 1)}$ *, 島田 広道 ${ }^{11}$, 佐藤 利夫 $^{\dagger 1)}$, 臀村 雄二 ${ }^{+1)}$, 松林 信行 ${ }^{\dagger 1)}$, 亀岡 隆 ${ }^{\dagger 2}$

†1)化学技術研究所, 305 茨城県つくば市東 1-1

+2)触媒化成工業(㨆，808 北九州市若松区北湊町 13-2

(昭和 62 年 3 月 19 日受理)

同一の物理性状を有するアルミナ担体でも，担体の調製法を変えることにより，モリブデン担持触媒の基本機能で ある水素化活性と水素化分解活性が制御できることがわかった。また,この原因として担体の化学性状が異なること, 化学性状の違いは担体調製過程でのアルミナ水和物の粒子形状および細孔発現挙動の違いによることが示唆された。 つぎに活性金属の担持状態を調べた結果，担体により活性金属の分散状態が異なることがわかり，基本活性の違いに 影響を与えたと考えられる。

\section{1. 緒 言}

モリブデン担持触媒は重質油の水素化处理触媒として広く用 いられており，その研究開発が多方面から進められている。現 在, モリブデン担持触媒の研究開発が進められている分野は, 中間留分の増産を目的として重質残油の水素化分解技術1), 才 イルサンド油およびオイルシェール油の改質精製技術 ${ }^{2}$ ，さら には石炭液化油の二次水素化および改質精製技術 ${ }^{3)}$ などの分野 であり，これらの研究開発をとおし，モリブデン担持触媒の水 素化活性および水素化分解活性などの基本機能の制御を行うこ とが必要不可欠であることが次第に明らかになってきた。すな わち, 重質油改質触媒として従来，ともすれば触媒寿命がその 研究開発の中心的課題であったが，モリブデン担持触媒の基本 機能である水素化活性および水素化分解活性を制御すること が, 出発原料を考虑した触媒活性および目的生成物を得るため の触媒選択機能の向上の面から要求されるようになってきた。 また, 触媒の水素化分解活性が触媒の酸性質と関連があり, 触 媒の酸性質は触媒上への炭素質の析出に影響を与えることを考 えれば，水素化分解活性と水素化活性の制御を行い触媒自体の 酸性質の制御を行うことも，触媒上への炭素質の析出に伴う触 媒活性の低下といった触媒寿命面からモリブデン担持触媒の制 御すべき重要な因子であることが明らかになってきた。

事実, 重質油の脱硫技術においてもモリブデン担持触媒の基 本機能である水素化活性および水素化分解活性の制御が行われ ており, 比較的軽質留分を対象とする間接脱硫技術においては, 相対的に高い水素化分解活性を有するモリブデン担持触媒が害 用に供されている。また，より重質留分を対象とする直接脱硫 技術においては，モリブデン担持触媒の水素化活性の向上をは

\footnotetext{
*連絡先
}

かり，水素化分解活性をむしろ抑制する試みがなされている。 一方, 石炭液化油, オイルサンド油, あるいはオイルシェール 油等は従来の石油系重質油と比べその性状が異なり, 例えば石 炭液化油の場合, 石油系重質油と比べ芳香族成分およびへテロ 原子を多く含むなど，これら重質油の水素化分解反応における 反応機構は石油重質油の場合と比べ著しく異なることが予想さ れる。このため, これらの重質炭化水素の改質あるいは精製反 応にモリブデン担持触媒を応用するにあたって, 以前にもまし て基本機能の制御が要求されるようになってきた。

近年, モリブデン担持触媒の水素化活性および水素化分解活 性などの基本機能の制御を目的として Ni-Mo, Co-Mo といっ た, Mo, Ni, Co, W などの活性金属種の組合せ, あるいは $\mathrm{P}$, $\mathrm{B}$ などの添加物による制御および, $\mathrm{SiO}_{2}-\mathrm{Al}_{2} \mathrm{O}_{3}, \mathrm{TiO}_{2}$ などと いった各種担体種の探索が行われている。4),5) また, 担体であ る $\gamma$-アルミナはモリブデン担持触媒の担体として実用的に最 も多く用いられており, 調製法の違いにより得られる担体性状 が異なることも知られている。吕7) しかしながら,これらの $\gamma-$ アルミナ担体に活性金属である Mo 等を担持した場合の担体 性状が Mo の担持状態およびモリブデン担持触媒としての水 素化活性拝よび水素化分解活性に与える影響はほとんど知られ ていない。そこで本研究では代表的な担体種である $\gamma$-アルミ ナと代表的な活性金属である Ni-Co-Moを選定し, 調製法の 違いによる担体の性状が，モリブデン担持触媒の担持状態およ び水素化活性と水素化分解活性に与える影響を詳細に検討し た。

本研究での触媒の水素化活性と水素化分解活性の評価は, モ デル化合物を選定し, 芳香環の水素化活性と C-C 結合の分解 活性で行うこととした。また, 実際の水素化处理反応とより良 い相関を求めるために高压水素下で反応を行うこととした。具 体的には, 水素化活性については 1-メチルナフタリンの 1-メ 
チルテトラリンと 5-メチルテトラリンへの環の水素化反応, 水素化分解活性についてはジフェニルメタンのトルエンとベン ゼンへの水素化分解反応により両者の性能評価を行った。また, 担体と触媒の物理性状および化学性状の解析には，それぞれ走 查型電子顕微鏡 $(\mathrm{SEM})$, 細孔分布測定装置および X 線光電 子分光装置 (XPS) などを用いた。

\section{2. 実殹}

\section{$2 \cdot 1$ アルミナ担体調製}

アルミナは, $\mathrm{pH}$, 濃度, 温度などの調製条件で，異なった 物理性状および化学性状を示すことが知られているが，ここで は $\mathrm{pH}$ および濃度を変えて検討を行った。

アルミナ担体は, 調合, 洗浄, 熟成, 濃縮, 成型, 乾燥, 焼 成の各工程により調製した（Fig. 1)。調製にあたり，まず異 なった濃度のアルミン酸ナトリウム水溶液（おのおのアルミナ 換算で $5 \mathrm{wt} \%$ と $22 \mathrm{wt} \%$ ）の硫酸アルミニウム水溶液（おの おの同じくアルミナ換算で $2 \mathrm{wt} \%$ と $7 \mathrm{wt} \%$ ）を調製した。つ ぎに, $\mathrm{A}$ 法ではアルミナとしての濃度 $5 \mathrm{wt} \%$ のアルミン酸ナ トリウム水溶液 $800 \mathrm{~g}$ を調合容器（ステンレススチール製, $\left.2,000 \mathrm{~cm}^{3}\right)$ に入れ，この水溶液をかくはんしながら濃度 $2 \mathrm{wt} \%$ の硫酸アルミニウム水溶液を $\mathrm{pH}$ が 7 になるまで添加し, 水 酸化アルミニウムのスラリーを生成させた。B 法ではアルミナ としての濃度 $5 \mathrm{wt} \%$ のアルミン酸ナトリウム $800 \mathrm{~g}$ を調合容 器（同上）に入れ，この水溶液をかくはんしながら濃度 $2 \mathrm{wt} \%$ の硫酸アルミニウム水溶液を $\mathrm{pH}$ が 9 になるまで添加し, 水 酸化アルミニゥムのスラリーを生成させた。C 法はアルミナ としての濃度 $22 \mathrm{wt} \%$ のアルミン酸ナトリウム水溶液と7 wt \% の硫酸アルミニウム水溶液を $\mathrm{pH}$ が 7 になるように調合 容器に同時に添加して水酸化アルミニウムのスラリーを生成さ せた。得られた各スラリーをフィルターによりろ別後, 希アン モニア水 $(0.2 \mathrm{wt} \%)$ で洗浄してスラリーに含まれる副生塩を

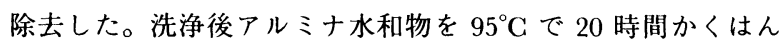
し熟成した。ついで,この熟成したアルミナ水和物を加温濃縮 して可塑性のあるアルミナ水和物とし，その水和物を押し出し 成型器を用い, 直径 $1 / 22$ インチの柱状物に成型した。この成 型物を $110^{\circ} \mathrm{C}$ で 16 時間乾燥後, $550^{\circ} \mathrm{C}$ で 3 時間焼成すること により各種のアルミナ担体（ $\gamma$-アルミナ）を調製した。

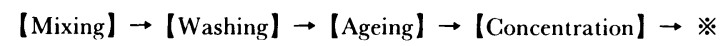

$$
\begin{aligned}
& \text { Washing with } \mathrm{NH}_{4} \mathrm{OH} \quad 95^{\circ} \mathrm{C} \cdot 20 \mathrm{~h} \\
& ※ \rightarrow\lfloor\text { Molding } \ \rightarrow\lfloor\text { Drying } \ \rightarrow \text { \Calcinning }\rfloor \\
& 1 / 22 \text { inch } \quad 110^{\circ} \mathrm{C} \cdot 16 \mathrm{~h} \quad 550^{\circ} \mathrm{C} \cdot 3 \mathrm{~h}
\end{aligned}
$$

\section{$2 \cdot 2$ 触媒}

Fig. 1 Preparation of Alumina Supports

触媒は, 触媒の組成が $4 \mathrm{wt} \% \mathrm{NiO}-4 \mathrm{wt} \% \mathrm{CoO}-14 \mathrm{wt} \%$ $\mathrm{MoO}_{3} / \mathrm{Al}_{2} \mathrm{O}_{3}$ になるように, 硝酸ニッケル, 硝酸コバルトお よびモリブデン酸アンモニウムから調製した Ni, Co, Mo 金属 塩水溶液を含浸担持し, $250^{\circ} \mathrm{C}$ で 1 時間乾燥後, $550^{\circ} \mathrm{C}$ で 1 時間焼成して調製した。

この触媒を, $5 \mathrm{vol} \% \mathrm{H}_{2} \mathrm{~S} / \mathrm{H}_{2}$ の硫化水素含有ガスを用い, $400^{\circ} \mathrm{C}, 1$ 時間の硫化処理を行い各種の反応に用いた。

$$
2 \cdot 3 \text { 触媒の活性評価 }
$$

各触媒の水素化活性および水素化分解活性の評価は，モデル 化合物を用いオートクレーブ $(50 \mathrm{ml})$ 中で行った。すなわち, 水素化（以下 HY と記述する）活性の評価は 1-メチルナフ夕 リン（1-MN）の水素化反応により得られる 1- および5-メチル テトラリンの収率を用い行った。一方, 水素化分解 (以下 $\mathrm{HC}$ と記述する）活性の評価はジフェニルメタン（DPM）の水素 化分解反応により得られるベンゼンとトルエンの収率を用い 行った。また, DPM の水素化分解反応では, 同時に生成する 水素化生成物（ベンジルシクロヘキサン）の収率を HY 活性 の指標とした。

反応条件は, 水素初圧: $6.9 \mathrm{MPa}$, 反応温度 : $350^{\circ} \mathrm{C}(\mathrm{HY}$ 活 性), $400^{\circ} \mathrm{C}$ ( $\mathrm{HC}$ 活性), 反応時間： $1 \mathrm{~h}$ である。反応後, 生成 物をオートクレーブより取り出し, キャピラリーカラム (HP, Ultra ${ }^{\# 1}, 50 \mathrm{~m}$ ）を備えたガスクロマトグラフ（島津, GC-9A） により各成分の定量を行った。

\section{$2 \cdot 4$ アルミナ担体の物性}

調製法の異なるアルミナ担体の調製過程における担体の物理 性状を調べるため, 各調製工程から得られる各種のアルミナ水 和物 (洗浄物, 熟成物), 成型乾燥物および焼成物の物性の測 定を行った。測定に際し,アルミナ水和物は $110^{\circ} \mathrm{C} て ゙ 16$ 時間 乾燥して用いた。比表面積㧍よび細孔容積（直径 $60 \mathrm{~nm}$ 以下 の細孔）を窒素吸着法（比表面積測定装置：Micromeritics. 2200, 細孔容積測定装置 : 定圧吸着装置) を用い測定した。さ らに, 定容吸着装置 (Micromeritics. 2100-01) を用い窒素吸着 等温線を求め, それより各種担体の細孔形状を調べると同時に B. J. H. 理論 ${ }^{8)}$ に基づき直径 $60 \mathrm{~nm}$ 以下の細孔の細孔径分布 を求めた。

つぎに，各手法のアルミナ調製過程におけるアルミナ粒子の 成長形態の変化を走査型電子顕微鏡 (SEM, 日本電子, JSMT100) で観察した。また, アルミナ水和物から $\gamma$-アルミナへ の変化の過程を, X 線回折装置 (XRD, 島津製作所, XD-3A) を用い擬アルミナベーマイトゲルの結晶化度を測定した。

アルミナの化学結合状態については, 熟成物と焼成物の電子 状態を, X 線光電子分光器 (XPS, 島津製作所, ASIX-1000) で測定したほか, 示差熱分析装置（D. T. A, 理学電機, 8100) により, 各手法の熟成物の示差熱 (DT) を測定した。さらに熱 重量分析装置（島津製作所, TG 31) を用い, $\mathrm{NH}_{3}$ 昇温脱離法 （TPD）で，焼成物の酸性質を測定した。

\section{$2 \cdot 5$ 触媒物性}

アルミナに担持された活性金属の分散状態を調べるため $\mathrm{X}$ 線マイクロアナライザー（XMA，島津製作所, ASM-SX)を 用い，触媒内部の活性金属の分布を測定した。また，触媒粒外 表面（成型体をそのまま測定）をXPS 装置を用いて測定し， 活性金属の組成および化学結合状態を解析した。

\section{3. 結果と考察}

\section{$3 \cdot 1$ 触媒の基本活性試殹}

各触媒の HY 活性と HC 活性の測定結果を Table 1 に示 す。アルミナ担体の調製方法が異なれば得られるモリブデン担 持触媒の HY 活性と HC 活性が異なってくることがわかった。 すなわち得られた担体が $\mathrm{HY}$ 活性に与える影響の序列は $\mathrm{B} \geqq \mathrm{A}$ $>\mathrm{C}$ であり, 一方, $\mathrm{HC}$ 活性に与える影響の序列は $\mathrm{C}>\mathrm{B} \geqq \mathrm{A}$ 
Table 1 Hydrogenation and Hydrocracking Activities of Various Catalysts

\begin{tabular}{c|cccc}
\hline Catalyst & $\begin{array}{c}\text { HY of 1-MN*1 } \\
(\%)^{* 4}\end{array}$ & $\begin{array}{c}\text { HC of DPM } \\
(\%)^{* 5}\end{array}$ & $\begin{array}{c}\text { HY of DPM } \\
(\%)^{* 3}\end{array}$ & $\begin{array}{c}\text { HC/HY*7 } \\
(-)\end{array}$ \\
\hline A & 29.2 & 32.5 & 14.8 & 2.2 \\
B & 31.1 & 35.0 & 13.0 & 2.7 \\
C & 23.1 & 39.8 & 7.3 & 5.4 \\
\hline
\end{tabular}

${ }^{* 1}$ Hydrogenation of 1-methylnaphthalene, ${ }^{* 2}$ Hydrocracking of diphenylmethane, ${ }^{* 3}$ Hydrogenation of diphenylmethane,

${ }^{*} 4$ Yields of 1 - and 5-methyltetralins, ${ }^{* 5}$ Yields of benzene and toluene, ${ }^{* 6}$ Yield of benzylcyclohexane, ${ }^{* 7}$ Yield ratio of HC to HY of DPM.

Table 2 Characteristics Properties of Alumina Supports

\begin{tabular}{|c|c|c|c|c|c|c|c|}
\hline \multirow{3}{*}{ Support } & \multirow{3}{*}{$\begin{array}{c}\mathrm{H}_{2} \mathrm{O}^{* 1} / \mathrm{Al}_{2} \mathrm{O}_{3} \\
\text { mol. ratio }\end{array}$} & \multirow{3}{*}{$\underset{\left(\mathrm{m}^{2} / \mathrm{g}\right)}{\text { S. A. }}{ }^{* 2}$} & \multirow{3}{*}{$\underset{\left(\mathrm{cm}^{3} / \mathrm{g}\right)}{\text { P. V. }}$} & \multicolumn{4}{|c|}{ Acidic property } \\
\hline & & & & \multirow{2}{*}{$\begin{array}{c}\text { Acidity } \\
\left(\mathrm{m} \cdot \mathrm{mol} / \mathrm{m}^{2}\right)\end{array}$} & \multicolumn{3}{|c|}{ Acid strength distribution $(\%)^{* 4}$} \\
\hline & & & & & $<300$ & $300 \sim 500$ & $500<\left({ }^{\circ} \mathrm{C}\right)$ \\
\hline $\begin{array}{l}\mathrm{A} \\
\mathrm{B} \\
\mathrm{C}\end{array}$ & $\begin{array}{l}1.6 \\
1.4 \\
1.6\end{array}$ & $\begin{array}{l}184 \\
191 \\
203\end{array}$ & $\begin{array}{l}0.80 \\
0.96 \\
0.75\end{array}$ & $\begin{array}{l}3.4 \times 10^{-3} \\
3.3 \times 10^{-3} \\
3.1 \times 10^{-3}\end{array}$ & $\begin{array}{l}21 \\
19 \\
27\end{array}$ & $\begin{array}{l}37 \\
34 \\
46\end{array}$ & $\begin{array}{l}42 \\
47 \\
27\end{array}$ \\
\hline
\end{tabular}

${ }^{* 1}$ Water of crystallization of alumina hydrates, ${ }^{* 2}$ Surface area, ${ }^{* 3}$ Pore volume (Pore volume with diameter smaller than 60 $\mathrm{nm}),{ }^{* 4} \%$ of acid site on which desorption of $\mathrm{NH}_{3}$ can be observed at temperature indicated.

であった。

また,これらの基本機能の違いは, 活性金属種あるいは担体 種を変えた場合ほど顕著ではないが，水素化脱硫活性に関係す ると考えられる $\mathrm{HC} / \mathrm{HY}$ 比は, 担体 A および B を用いた場合 と担体 $\mathrm{C}$ を用いた場合とでは大きく異なっている。これらの 事実は，担体 $\mathrm{A}$ および $\mathrm{B}$ と担体 $\mathrm{C}$ で担体の性状が異なり, 活性金属種と担体の相互作用が異なるため, 触媒の基本活性で ある HY 活性と HC 活性に差が生じたことを示唆していると 考えられる。そこで, これらの原因を解明するため, 焼成後の 各種アルミナ担体の性状の違いをまず検討した。

\section{$3 \cdot 2$ アルミナ担体の性状}

\section{$3 \cdot 2 \cdot 1$ 烧成後のアルミナ担体の性状}

Table 2 に成型, 焼成後の担体の性状を示す。各手法で得 られた $\gamma$-アルミナの性状は, 細孔容積に若干の違いが認めら れたが, 含有結晶水, 比表面積および細孔形状（Fig. 6) には 大きな違いは認められなかった。また，SEMにより測定した アルミナ粒子の形状でも違いは認められなかった。

一方，酸性質については Table 2 に示すように酸量は担体 $\mathrm{A}, \mathrm{B}$ 抢よび $\mathrm{C}$ 間で違いはあまり認められなかったが, 酸強度 は担体 $\mathrm{A}$ および $\mathrm{B}$ と担体 $\mathrm{C}$ で異なっていることがわかった。 すなわち, 担体 $\mathrm{C}$ では担体 $\mathrm{A}$ および $\mathrm{B}$ と比べ, $300 \sim 500^{\circ} \mathrm{C}$ あるいは $300^{\circ} \mathrm{C}$ 以下で脱離する $\mathrm{NH}_{3}$ 量が多く，担体 $\mathrm{A}$ およ び B では $500^{\circ} \mathrm{C}$ 以上でも吸着している $\mathrm{NH}_{3}$ 量が多いことが わかり，両者で酸強度分布が異なることが明らかになった。ま た, 各手法の担体焼成品の残存 $\mathrm{Na}^{+}$と $\mathrm{SO}_{4}{ }^{2-}$ の分析を行っ たところ, $\mathrm{Na}^{+}$については各手法間で違いは認められなかっ たが, $\mathrm{SO}_{4}{ }^{2-}$ については担体 $\mathrm{C}$ は担体 $\mathrm{A}, \mathrm{B}$ に比べ高濃度の $\mathrm{SO}_{4}{ }^{2-}$ を含有していることがわかり，これも担体間での酸強 度分布の違いに影響を与えていると考えられる。一方，これら アルミナ担体の酸強度分布の違いが直接 HC 活性の違いに影 響を与えるとは考えられず，事実，アルミナ担体のみではゼオ ライト等の場合と異なり，モデル反応において HC および HY のいずれの活性も示さない。しかしながら，活性金属の担
持状態は担体の性状により影響を受けることが知られてお $\eta^{9)}$, 担体の酸強度分布が異なれば活性金属である Mo, Co お よび $\mathrm{Ni}$ の担持状態が異なることが予想される。このため，担 体 $\mathrm{C}$ では触媒調製さらには硫化後 $\mathrm{HC}$ 活性に有効となる活性 サイトが相対的に多く存在し，これらは $300 〜 500^{\circ} \mathrm{C}$ あるいは $300^{\circ} \mathrm{C}$ 以下で脱離した $\mathrm{NH}_{3}$ に対応する酸点に起因すると考え られる。300 $500^{\circ} \mathrm{C}$ の $\mathrm{NH}_{3}$ の脱離量に対応する酸点の量は 担体 $\mathrm{C}>$ 担体 $\mathrm{A} \geqq$ 担体 $\mathrm{B}$ の順であり,この結果はモデル反応 で得られた HC 活性の序列と一致することがわかった。

以上，焼成後の担体では担体の物理性状はほとんど同じであ るが，担体の化学性状が担体調製手法によって異なることが明 らかになり,これが最終的に予備硫化後の触媒の基本性能に影 響を与えたと考えられる。つまり担体 C では触媒調製後 $\mathrm{HC}$ 活性の発現に有効と考えられる酸点を多く有しており，これが 硫化後の触媒の高い HC 活性に寄与しているものと考えられ る。一方, 担体 $\mathrm{A}$ および $\mathrm{B}$ では触媒調製後 $\mathrm{HC}$ 活性の発現に 寄与する酸点が少ないことから，硫化後の触媒においても HC 活性は低く相対的に高いHY 活性を示すと考えられる。また, 焼成後アルミナ担体の酸性質が異なることは，アルミナ担体の 調製過程でのアルミナ水和物の物理性状あるいは化学性状の違 いに起因すると考えられる。

そこで, 担体の調製過程でのアルミナ水和物の物理性状およ び化学性状の検討を行った。

\section{$3 \cdot 2 \cdot 2$ 調製過程におけるアルミナ水和物の物理性状}

各手法のアルミナ調製過程におけるアルミナ水和物粒子の成 長形態をSEM より測定した結果を Fig. 2 に示す。

これらよりアルミナ粒子の成長は, 水和物の過程で板状ある いはブロック状の粒子ができ, 濃縮と焼成の過程でさらに成長 すると考えられる。さらに，各手法においてアルミナ粒子の成 長過程を詳細に検討すると, A 法では洗浄後微粒子が凝集し て板状物を形成し，その上に新たな粒子が成長して凝集すると いった過程を繰り返しながらアルミナ水和物が層状に成長する こと, B 法では洗浄後すでに板状の粒子ができており， A 法 

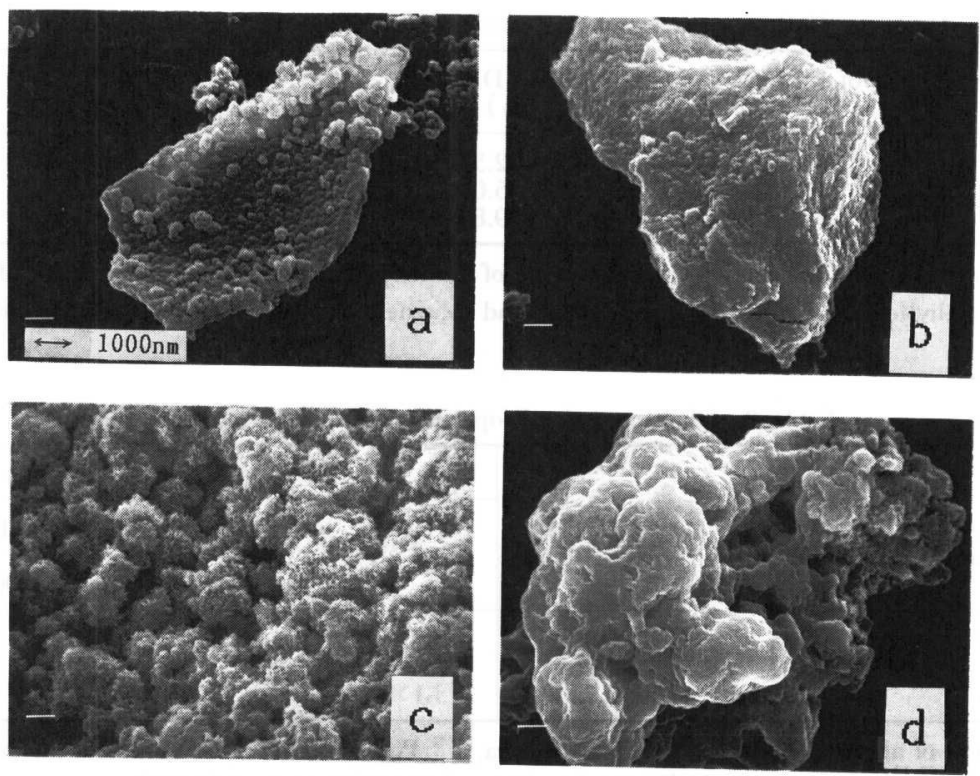

Fig. 2 Scanning Electron Micrographs of Various Aluminas

a : Dried material of washed slurry of A prescription

b : Dried material of washed slurry of $\mathbf{B}$ prescription

c : Dried material of washed slurry of $\mathrm{C}$ prescription

d : Dried material of aged slurry of $\mathbf{C}$ prescription

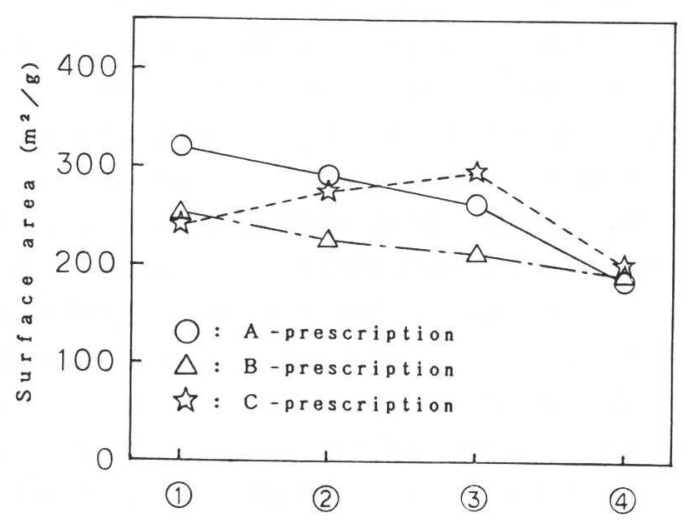

Fig. 3 Change in Surface Area of Aluminas by the Processes of Preparation
(1) : Dried materials of washed slurry
(2) : Dried materials of aged slurry
(3) : Extruded dried molding
(4) : Extruded calcined molding

にみられる粒子の成長過程はみられないことなどがわかった。 一方, C 法では洗浄後板状物が不規則に層状に積み重なり大 きな空孔を有してブロック状の粒子を生成することおよびフ ロック状表面には海綿状のものも存在することなど, 明らかに 各手法により相違が見られた。

つぎに, アルミナ調製過程における細孔構造の形成過程につ いて, 比表面積 (Fig. 3), 細孔容積 (Fig. 4) および細孔径分 布（Fig. 5) を示す。各手法における細孔構造形成において, A 法は熟成過程で小細孔が減少し, その後は乾燥, 焼成過程 で比表面積の増加に寄与が少ない $10 \mathrm{~nm}$ 以上の細孔径を有す

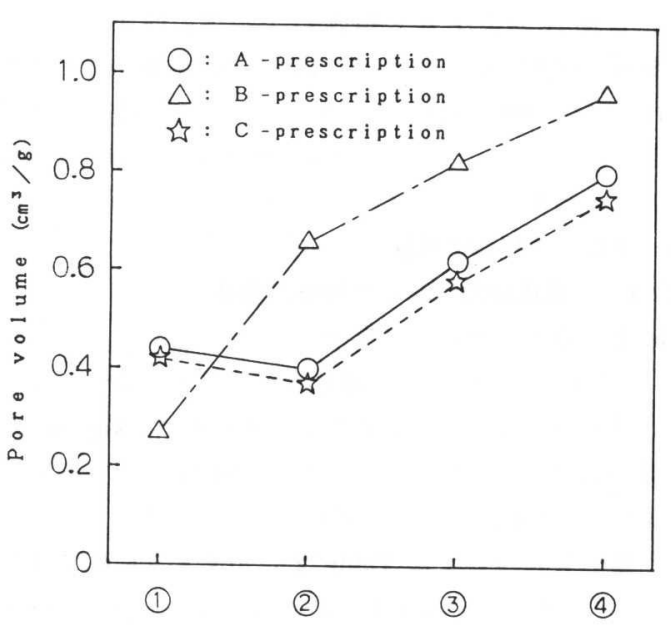

Fig. 4 Change in Pore Volume of Aluminas by the Processes of Preparation
(1) : Dried materials of washed slurry
(2) : Dried materials of aged slurry
(3) : Extruded dried molding
(4) : Extruded calcined molding

る細孔が生成していることがわかる。B 法でも熟成過程で小細 孔が減少し, 比表面積は隇少傾向にある。しかし，B 法では熟 成過程で細孔容積の増加が認められた。一方， C 法では A お よび B 法とは逆に熟成過程で比表面積が増加し, 細孔容積が 減少することから, 小細孔（10 $\mathrm{nm}$ 以下）が形成されることが わかった。また, C 法では濃縮, 乾燥工程でも他の A および $\mathrm{B}$ 法と異なり, 比表面積の増加に寄与する小細孔が生成してい 
ることも見い出された。

つぎに，担体調製過程で得られた吸着等温線 (Fig. 6) から

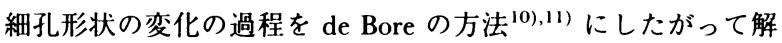
析を行った。A 法と C 法のアルミナ水和物では層状構造に多 くみられるスリット型細孔を形成しており，この結果はSEM の観測結果と一致している。一方, B 法ではアルミナ水和物に おいてインクボトル型細孔を形成しており, 他の A 法および C 法と異なった細孔形状を示した。特に, 洗浄後のアルミナ 水和物は de Bore の分類では E 型を示しており狭ロインクボ トル型細孔を形成していると思われる。しかし，成型乾燥後あ るいは焼成後では調製法に関わりなく円筒形に近いインクボト ル型細孔に変化しており，明確な違いは見い出せなかった。
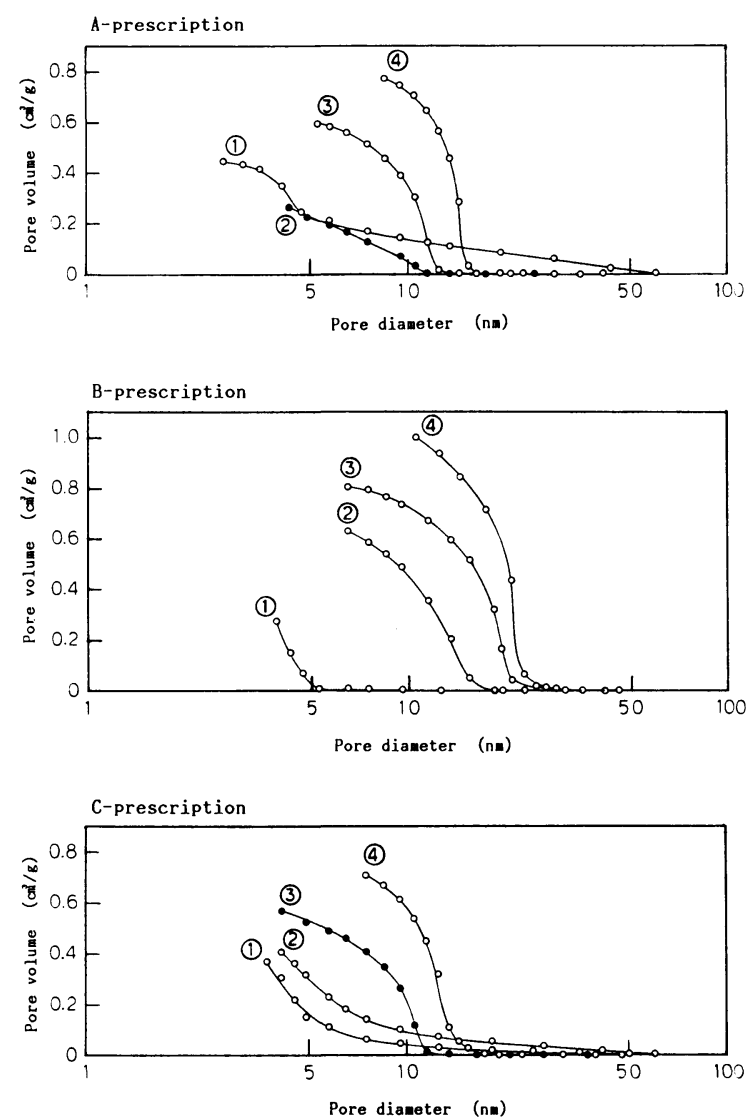

Fig. 5 Change in Pore Size Distribution of Aluminas by the Processes of Preparation

(1) : Dried materials of washed slurry

(2) : Dried materials of aged slurry

(3) : Extruded dried molding

(4) : Extruded calcined molding
以上，各手法の調製過程におけるアルミナ水和物粒子の形態 および細孔構造を測定した結果, 洗浄, 熟成, 乾燥, 焼成過程 で，A および B 法と C 法で粒子形状および細孔構造の発現挙 動が異なることが明らかになった。これは調合過程でのアルミ ン酸ナトリウムや硫酸アルミニウム水溶液の濃度および調合 $\mathrm{pH}$ などの調製条件の違いによるものと考えられる。一方，焼 成後担体 $\mathrm{A}$ およびB と担体 $\mathrm{C}$ で物理性状は同じであるが化学 性状が異なるという $\mathbf{3} \cdot \mathbf{2} \cdot \mathbf{1}$ で得られた結果を併せて考える と，つぎの二つのことが推察できる。まず第一の推察は，担体 調製過程での物理性状の違いが, 乾燥および焼成過程での酸点 の発現などに影響をおよほし，焼成後の担体の化学性状を变え たという考え方である。第二の考え方は，すでに熟成，濃縮過 程でアルミナ水和物の化学性状が異なっており，これが焼成後 の化学性状に影響を与えるという推察である。

そこで, 調製過程におけるアルミナ水和物の化学性状につい て検討した。

\section{$3 \cdot 2 \cdot 3$ 拥製過程におけるアルミナの化学性状}

Fig. 7 に各手法のアルミナ水和物（熟成物）のDT 曲線を 示す。この結果 B 法では他の手法に比べ $\alpha$-アルミナへの相転 移温度および $400 \sim 500^{\circ} \mathrm{C}$ における $\gamma$-アルミナへの相転移温 度が高く，また吸熱反応ピークがシャープであることから化学 状態がもっとも安定していると考えられる。A 法と C 法につ いては, C 法の方が $\alpha$-アルミナへの相転移温度が高いことか ら A 法に比べ安定状態にあると推測される。

つぎに,アルミナ水和物 (熟成物) から焼成物の過程で $\mathrm{Al}$ の電子状態（XPSによる Al 2p の測定）を調べた結果，A 法 がもっとも大きな変化を示した $($ Table 3)。この結果は示差 熱分析の結果を支持しており，B 法によって得られたアルミナ がもっとも化学安定性が高いことがわかった。また, 擬べーマ イトアルミナ水和物の結晶化の变化を調べた結果 (Fig. 8), 結晶成長は B 法が最も大きく，これは調製時に他の手法に比 ベ $\mathrm{B}$ 法ではアルミナ水和物が安定状態下で徐々に成長し結晶 化したことを示している。しかし，焼成するといずれも $\gamma-ア$ ルミナに変化しており, 各手法で焼成後の結晶性の違いは認め られなかった。

以上，アルミナ担体の調製過程でアルミナ水和物の物理性状 および化学性状を調べた結果, C 法では A 法および B 法に比 べ調製過程でアルミナ水和物の粒子形状および紐孔の発現挙動 が異なることが明らかになり，これは調合時のアルミナ濃度の 違いによるものと考えられる。12) また，B 法では化学結合状 態が $\mathrm{A}$ および $\mathrm{C}$ 法と異なることがわかり，これは調合 $\mathrm{pH}$ の 違いによるものと考えられる。これらの結果を触媒基本機能の 結果 $(\mathbf{3} \cdot \mathbf{1})$ と併せて考えると担体調製過程でのアルミナ水和 物の粒子形状および小細孔の発現挙動の違いが, 乾燥, 焼成過

Table 3 Shift in Al 2p Photoelectron Spectra of Alumina Supports

\begin{tabular}{c|ccc}
\hline \multirow{2}{*}{ Support } & \multicolumn{3}{c}{ Al 2p photoelectron spectra $(\mathrm{eV})$} \\
\cline { 2 - 3 } & Aged alumina*1 & Calcined alumina*2 & Degree of shift \\
\hline A & 73.80 & 74.20 & 0.40 \\
B & 73.80 & 74.00 & 0.20 \\
C & 73.90 & 74.10 & 0.30 \\
\hline
\end{tabular}

${ }^{* 1}$ Dried materials of aged slurry, ${ }^{* 2}$ Extruded calcined molding 

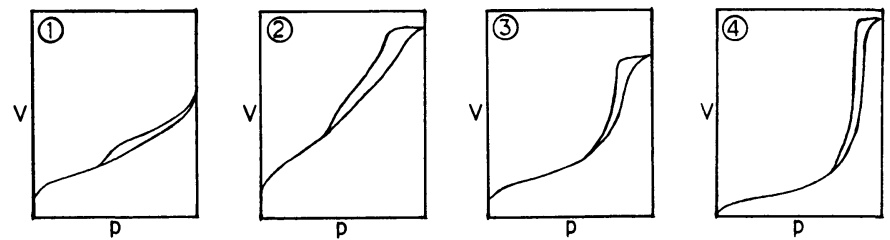

B-prescription
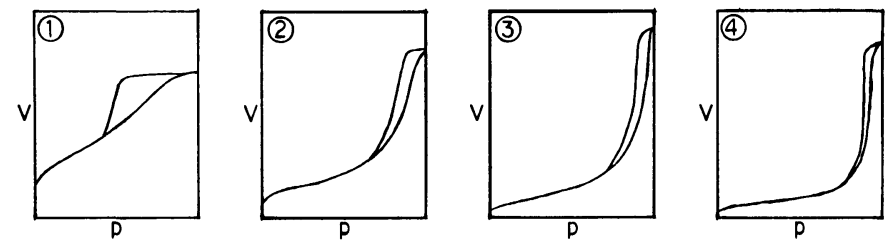

C-prescription
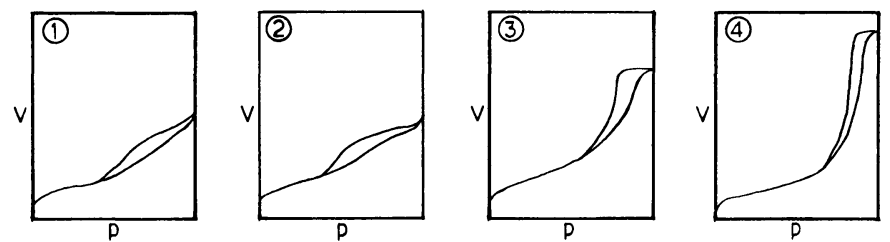

Fig. 6 Change in Pore Shape of Aluminas by the Processes of Preparation

(1) : Dried materials of washed slurry

(3) : Extruded dried molding

(2) : Dried materials of aged slurry

(4) : Extruded calcined molding

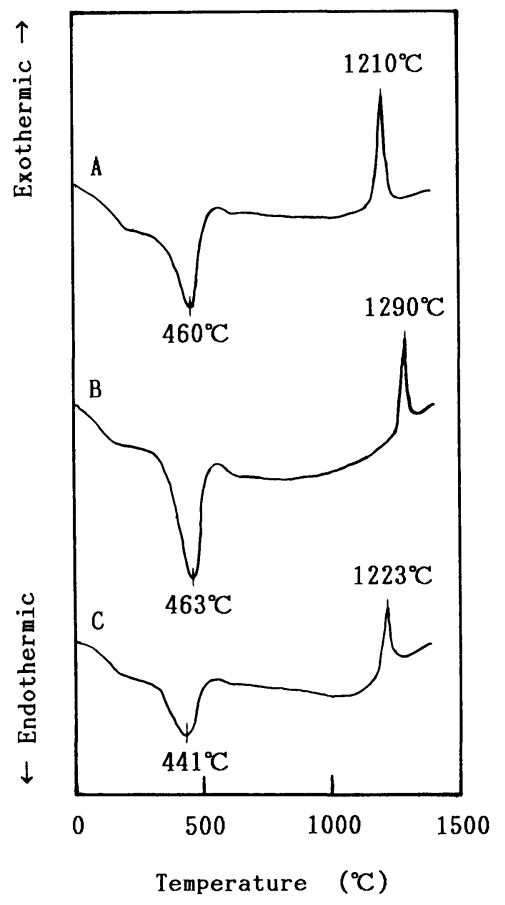

Fig. 7 Differential Thermal Analysis Patterns of Dried Materials of Aged Slurry
A : A-prescription
B : B-Prescription
C : C-prescription

程での酸点の生成に大きな影響を与えると考えられる。一方, 担体調製過程で認められたアルミナ水和物の化学性状の違い が, 焼成後のアルミナ担体の化学性状に与える影響は比較的小 さいと考えられる。

つぎに，担体の酸性質が異なれば活性金属の担持状態も異 なってくると考えられる。そこで, 活性金属の担持状態につい て検討した。

\section{$3 \cdot 3$ 活性金属の担持状態}

触媒粒断面における活性金属の分布状態を XMAにより測 定した結果 (Fig. 9), いずれの触媒においても Ni, Co, Mo の 各活性金属種が，XMA の検出限界 (XMA の空間分解能は $\mu \mathrm{m}$ オーダー)では均一に分散担持されていることがわかった。 つぎに，XPS と Ar イオン衝撃法を併用して触媒粒外表面で の活性金属の深さ方向の分析（スパッタリング速度は 20 分間 で約十数 $\mathrm{nm}$ 程度と考えられる) を行った結果 (Fig. 10), 担 体 $\mathrm{A}, \mathrm{B}$ を用いた触媒では担体 $\mathrm{C}$ に比べ，担体粒外表面層で 活性金属の濃縮がおこっていることがわかった。活性金属の濃 度は触媒 $\mathrm{A} \geqq$ 触媒 $\mathrm{B}>$ 触媒 $\mathrm{C}$ であり,この結果は HY 活性の 序列と一致した。なお，活性金属 $\mathrm{Ni}$ および Co の表面での濃 縮挙動は Mo の場合と同様であった。

これらの結果は, 担体 $\mathrm{A}$ および $\mathrm{B}$ 上において活性金属の状 態は微粒子で均一に担持されており, 担体 $\mathrm{C}$ 上では比較的大 きな粒子を形成しているためと考えられ（Fig. 11)，この担体 $\mathrm{A}, \mathrm{B}$ 上における活性金属の高分散状態は, HY 活性の向上に 寄与していると考えられる。9

つぎに，各担体上に担持された Mo の電子状態をXPS で分 
(1)

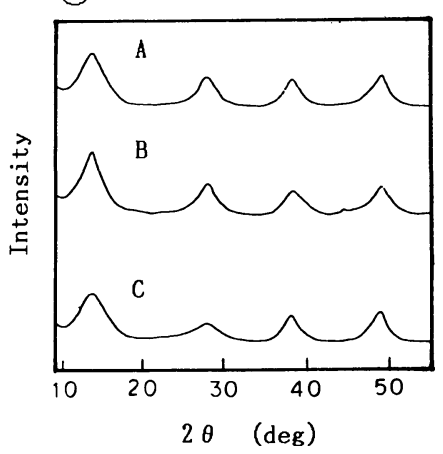

(2)

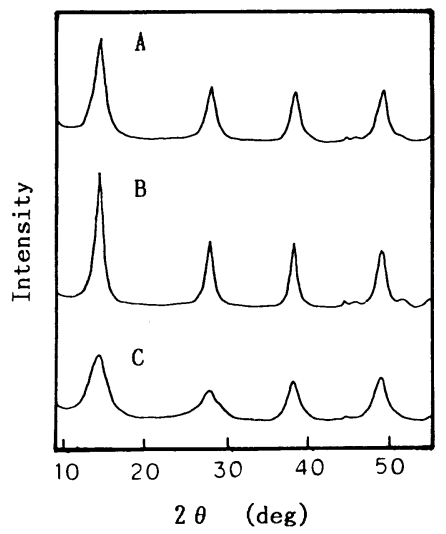

(3)
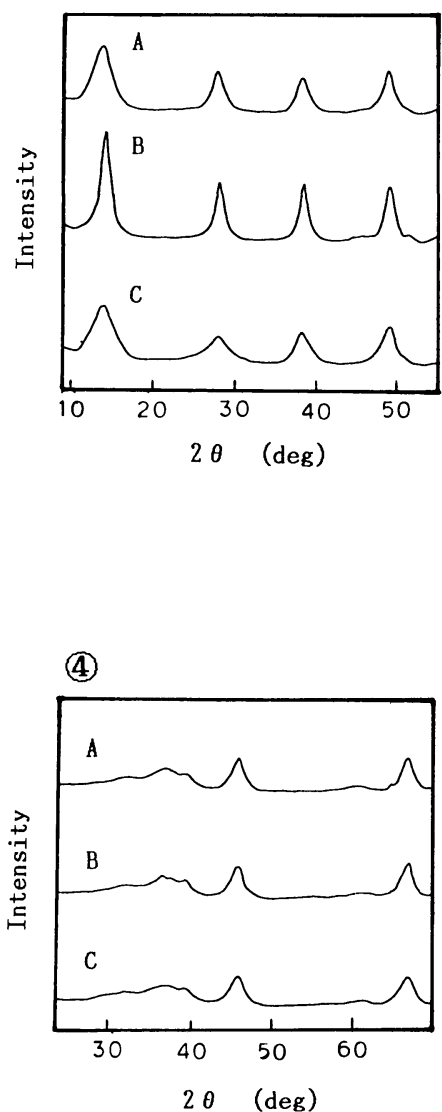

Fig. 8 Change in X-ray Diffraction Patterns of Aluminas by the Processes of Preparation A : A-prescription, B : B-prescription, C : C-prescription
(1) : Dried materials of washed slurry
(3) : Extruded dried molding
(2) : Dried materials of aged slurry
(4): Extruded calcined molding

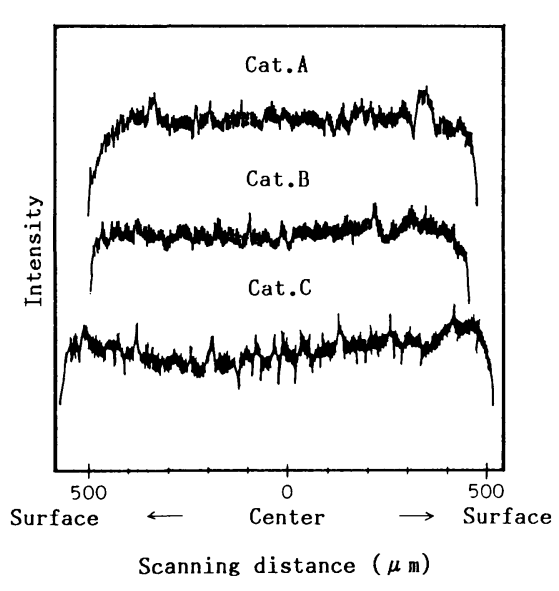

Fig. 9 The Concentration Profile of Molybdenum on the Catalysts Measured by XMA

析した結果 (Fig. 12), 担体 C ではMo $3 \mathrm{~d}_{5 / 2}$ と Mo $3 \mathrm{~d}_{3 / 2}$ 光 電子スペクトルの分離が明りょうでなく, Mo 3d 光電子スペ クトルの線幅がブロードニングをおこしていることが予想され る。そこで, ガウス関数に基づいてスペクトルの波形分離を行

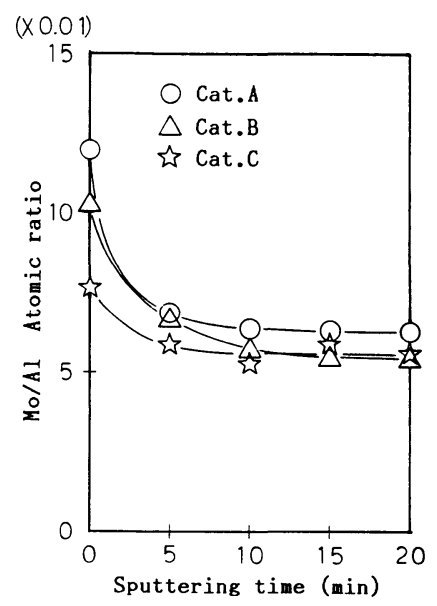

Fig. 10 The Concentration Profile of Molybdenum of Around External Surface of the Catalysts Measured by XPS

い各スペクトルの半值幅を求めて比較したところ, 担体 C で は担体 A, B の場合と比べ半值幅が広く光電子スペクトルがブ ロードであることがわかった。このことは担体 $\mathrm{C}$ 上で異なっ 

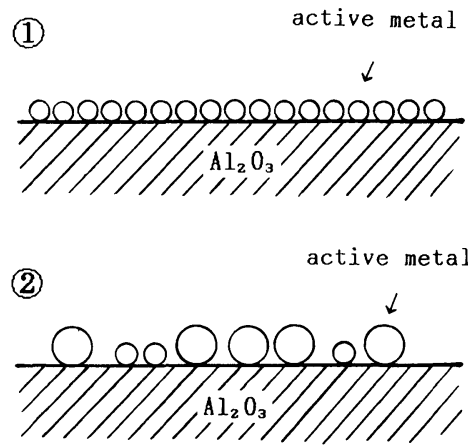

Fig. 11 Schematic Representation of Species with Different Initial Dispersions on a Catalyst Surface

(1) : Dispersion condition on the A and B supports

(2) : Dispersion condition on the $\mathrm{C}$ support

た Mo の担持状態が存在することを示唆している。すなわち, 担体 $\mathrm{A}$ および $\mathrm{B}$ 上では，Mo が微粒子として存在し Mo 原子 の担持状態がほほ同じであるのと異なり，担体 $\mathrm{C}$ 上では微粒 子の外に比較的大きな Mo 粒子が成長しているため, Mo 原子 と担体との相互作用が原子により異なり, 幅広いMoの電子 状態が存在すると考えられる。

以上，得られた担体 $\mathrm{C}$ 上での Mo の光電子スペクトルのブ ロードニングは，担体 $\mathrm{C}$ 上で活性金属である Mo が担体 $\mathrm{A}, \mathrm{B}$ 上と比べ異なった電子状態を有する活性種が存在することを示 唆しており，これが担体 $\mathrm{C}$ 上での $\mathrm{HC}$ 活性の発現に関与する と考えられる。

\section{4. 結 言}

本研究では担体として $\gamma$-アルミナを選定し，モリブデン担 持触媒の基本機能である水素化活性と水素化分解活性の制御を 試みた。具体的にはまず三種の異なった手法によりアルミナ担 体を調製し，担体の物理性状をほほ同一になるように調製した。 活性金属担持後，モリブデン担持触媒の水素化活性と水素化分 解活性をモデル反応により測定し，担体によりこれらの性能が 異なることを明らかにした。

つぎに，担体の酸性質を調べた結果，担体 $\mathrm{C}$ が他の担体 $\mathrm{A}$ および $\mathrm{B}$ に比べ，触媒調製後水素化分解活性に有効となる酸 点が多いことを見い出し，この原因で考えられるアルミナ調製 過程でのアルミナ水和物の物理性状および化学性状を調べた。 この結果, 担体 $\mathrm{C}$ では成長過程でのアルミナ水和物の粒子形 状および細孔の発現挙動が異なることがわかり,これが乾燥, 焼成後の担体の化学性状に影響を与えたと考えられる。

一方, 担体の化学的性質が異なれば活性金属の担持状態が異 なることが予想され，事実，XPS などの実験結果から担体 A および B では活性金属が微粒子で分散しており，担体 $\mathrm{C}$ 上で は比較的大きな粒子に成長していることが示唆された。担体 $\mathrm{A}$ および B 上における活性金属の高分散状態は結果として水 素化活性の向上に寄与していると考えられる。また担体 $\mathrm{C}$ 上 で予想される比較的大きな粒子は，担体との相互作用が粒子中 の金属イオンにより異なると考えられる。このため異なった Mo の電子状態が存在し, 一部が最終的に水素化分解活性の向 上に寄与していると考えられる。

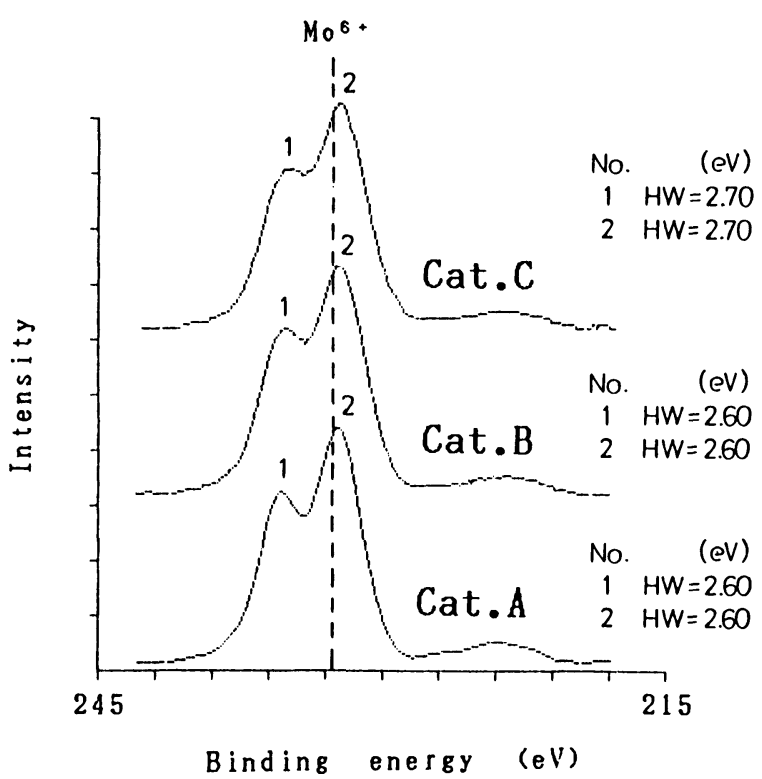

Fig. 12 Mo 3d Photoelectron Spectra of Catalysts

No. 1 : Mo $3 \mathrm{~d}_{3 / 2}$ photoelectron spectra No. 2 : Mo $3 d_{5 / 2}$ photoelectron spectra HW : Half width

以上，本研究によって担体として $\gamma$-アルミナを用いた場合， アルミナ担体の調製手法を制御すれば担体性状を変えることが 可能であり, モリブデン担持触媒の基本機能である水素化活性 と水素化分解活性を制御できることが明らかになった。今後, 水素化活性と水素化分解活性の制御に向けて活性金属担持手法 の検討など,さらに詳細な検討が必要である。

\section{References}

1) Jushitsuyu Taisaku Gijutsu Kenkyu Kaihatsu no Doko (重質油対策技術研究開発の動向), July, 1986.

2) Shin Nenryoyu no Kenkyu Kaihatsu (VII), Kokai Nenpo (新燃料の研究開発(VII), 公開年報), 1986.

3) Nishijima, A., Shimada, H., Sato, T., Yoshimura, Y., Rroc. Intern. Conf. Coal Science, Sydney, 201, 1985.

4) Shimada, H., Sato, T., Yoshimura, Y., Hiraishi, J., Nishijima, A., Shokubai, 27, (6), 404 (1985).

5) Tanabe, K., Hattori, H., Sekiyu Gakkaishi, 29, (4), 280 (1986).

6) Jpn. Tokkyo Koho JP 74 31, 597.

7) Jpn. Tokkyo Koho JP 78 120, 691.

8) "Shokubai Kagaku Koza 4, Shokubai Kiso Sokuteiho" (触媒化学講座 4, 触媒基礎測定法), Shokubai Gakkaihen（触媒学会編）, p. 73-79, 1965.

9) Nishijima, A., Shimada, H., Sato, T., Yoshimura, Y., Hiraishi, J., Polyhedrpn, 5, (1/2), 243 (1986).

10) De Bore, J. H., The shape of capillaries, in "The Structure and Properties of Porous Materials", D. H. Everett and F. S. Stone, eds., (1958), Btterworth, London.

11) De Bore, J. H. Lippens, B. C., J. Catalysis, 3, 38-43, (1964).

12) Yamadaya, S., Shimomura, K., Kinoshita, T., Uchida, H., Kogyo Kagaku Zasshi, 72, 1050 (1969). 


\title{
Summary
}

\section{Control of Hydrogenation and Hydrocracking Activities of Molybdenum Sulfide Catalysts Supported on Alumina -Effect of Preparation Condition of Alumina on Functionalities of Catalysts-}

\author{
Akio Nishijima $^{\dagger 1)}$, Hiromichi Shimada ${ }^{\dagger 1)}$, Toshio Sato ${ }^{\dagger 1}$, \\ Yuji Yoshimura $^{\dagger 1}$, Nobuyuki Mathubayashi ${ }^{\dagger 1}$, and Takashi KameOKa ${ }^{\dagger 2)}$ \\ 11) National Chemical Laboratory for Industry, \\ 1-1 Higashi, Tsukuba, Ibaraki 305 \\ †2) Catalyst and Chemicals Industries Co., Ltd, 13-2 Kitaminato-machi, \\ Wakamatsu-ku, Kitakyushu 808
}

The relation between the hydrogenation (HY) and hydrocracking (HC) activities of $\mathrm{NiO}-\mathrm{CoO}-\mathrm{MoO}_{3} /$ $\mathrm{Al}_{2} \mathrm{O}_{3}$ catalysts and the methods for preparation of $\mathrm{Al}_{2} \mathrm{O}_{3}$ support were investigated in order to control the catalytic functionalities of molybdenum catalysts. Two kinds of model test reactions were carried out to clarify $\mathrm{HY}$ and $\mathrm{HC}$ activities of the catalysts. The HY and HC activities, shown in Table 1, were different on the different support, though some of the physical properties of the support were almost identical with each other. Some of the chemical properties of the supports were different from each other, as shown in Tables 2 and 3. In order to elucidate the difference in the chemical properties of the support after drying and calcining, the changes in the physical and chemical properties of aluminium hydroxide in the process of alumina formation were investigated. Figures 2 to 8 and Table 3 show the changes of the properties of aluminium hydroxide in the course of preparation. As shown in Figures 2,4,5 and 6, the differences in particle shape and pore structure during the growth of aluminium hydroxide precipitates seem to be related with the chemical properties of $\mathrm{Al}_{2} \mathrm{O}_{3}$, after calcination. The interaction between support and active metal also depends on the type of support used. The results, after analysing the data obtained by XPS and Ar ion bombardment of three types of catalysts, showed the difference in the distribution and dispersion of molybdenum ions on surfaces of catalysts prepared differently (Fig. 9). These differences seem to lead to a conclusion explaining the catalytic functionalities of the molybdenum catalysts. Higher dispersion of molybdenum ion seems to give higher HY activity (Fig. 11), and proper gathering of molybdenum ions seems to give higher HC activity through the different electronic state of the molybdenum ions (Fig. 12). More detailed researches may be necessary for fully understanding the relation between the catalytic functionalities and the structure of $\mathrm{MoO}_{3} / \mathrm{Al}_{2} \mathrm{O}_{3}$ catalysts.

\section{Keywords}

Active site, Catalyst preparation, Molybdenum catalyst, Selectivity, Support effect, Surface property 